\title{
Nurses' Supplemental Oxygen Therapy Knowledge and Practice in Debre Tabor General Hospital: A Cross-Sectional Study
}

This article was published in the following Dove Press journal: Open Access Emergency Medicine

\author{
Shegaw Zeleke $\mathbb{D}^{\prime}$ \\ Demewoz Kefale ${ }^{2}$ \\ 'Department of Adult Health Nursing, \\ College of Health Sciences, Debre Tabor \\ University, Debre Tabor, Ethiopia; \\ ${ }^{2}$ Department of Pediatric and Child \\ Health Nursing, College of Health \\ Sciences, Debre Tabor University, Debre \\ Tabor, Ethiopia
}

Background: Oxygen therapy is a medical treatment and prescribed to prevent or treat hypoxemia. Based on a WHO report every year at least 1.4 million deaths occur due to the lack of supplemental oxygen therapy and inappropriate administration of oxygen.

Objective: To assess the knowledge and practice of nurses on supplemental oxygen therapy in Debre Tabor General Hospital, 2019.

Methods: Data was collected using structured questionnaires that measure nurses' knowledge and practice regarding supplemental oxygen therapy. Data were entered using Epi Data version 3.1 and analyzed using SPSS version 23. Bivariate and multivariate analyses were conducted to examine the association between independent and outcome variables.

Results: Only one-third of nurses had a good practice on supplemental oxygen administration. Nurses who had good knowledge of supplemental oxygen administration were 12-times $(\mathrm{AOR}=12.25,95 \% \mathrm{CI}=6.48-32.93)$ more likely to have a good practice of supplemental oxygen administration than those who had poor knowledge of supplemental oxygen administration.

Conclusion: There is a clear knowledge and practice gap among nurses working in Debre Tabor General Hospital. The knowledge and practice level of nurses in the study area is low compared with others. The possible factors were identified; such as lack of supplemental oxygen therapy training, absence of supplemental oxygen administration standard guidelines, workload, and inadequate supply of oxygen and delivery devices.

Keywords: knowledge, practice, supplemental oxygen therapy, nurse

\section{Introduction}

Supplemental oxygen therapy (SOT) is a medical treatment used for tissue hypoxia. It has the potential to improve medical outcomes and save lives when used appropriately and to cause harm if used inappropriately. ${ }^{1}$ Oxygen is listed as a core item on the World Health Organization's (WHO) model of essential medicines used in a healthcare system. ${ }^{2}$ Administering SOT has an essential role in preventing and managing hypoxemia in both acute and chronic conditions. SOT is considered as a key instrument in resuscitating patients during general evaluation. ${ }^{3,4}$ SOT has a pivotal role in saving the lives of many patients with heart and lung diseases if used at an appropriate time and in an appropriate amount according to WHO updated guidelines. $^{2,5}$ The British Thoracic Society guideline for emergency oxygen use in adult patients emphasized the achievement of normal or near-normal oxygen saturation level for the majority of patients in an emergency department or intensive care unit. ${ }^{6}$ 
The optimal amount and method of oxygen delivery varies depending on a patient's underlying medical condition and whether the condition is acute or chronic. The selection of the best oxygen delivery device and flow rate of oxygen depends on many factors, some of which are the patient's age, the therapeutic goals, and patient tolerance. ${ }^{7,8}$ Oxygen should be prescribed to achieve a target saturation of $94-98 \%$ for most acutely ill patients or $88-92 \%$ for those at risk of hypercapnia respiratory failure. ${ }^{9}$ Oxygen can easily dehydrate exposed membranes in the upper respiratory tract unless patients are orally rehydrated and/or mouth care is given, along with humidification, which can mobilize secretions and enhance patient comfort. ${ }^{10}$ Therefore, oxygen should be administered by staff that are trained in oxygen administration. But, there are significant gaps regarding oxygen therapy, despite it's frequent use. ${ }^{11}$ Nurses are the most responsible health personnel who monitor oxygen therapy and reduce supplementary oxygen risk as soon as possible. ${ }^{12}$ Based on research studies conducted in different countries there is a knowledge and practice gap on oxygen therapy among practicing nurses in hospitals. ${ }^{6,12-15}$ To the authors' knowledge, it is hard to find studies that have been conducted in the study setting to identify the knowledge and practice of nurses in public hospitals. Therefore, this study aims to assess and identify factors associated with the knowledge and practice of nurses on SOT.

\section{Methods}

\section{Study Setting and Design}

The study was carried out in Debre Tabor General Hospital, which is found in North Central Ethiopia. Debre Tabor is located 50 kilometers east of Lake Tana and 665 kilometers from the capital city of Ethiopia, Addis Ababa. The study was conducted from November 1, 2019 to December 1, 2019.

\section{Population and Sampling}

All nurses $(\mathrm{N}=105)$ working in Debre Tabor General Hospital were included in the study. Since the study population was small, we did not determine the sample size, rather a census was conducted.

\section{Study Variables, Tools, and Data Collection Procedure}

The outcome variables were the knowledge and practice of nurses on supplemental oxygen therapy. Data collection was done by two nurse research team members who were trained to observe proper oxygen administration. The data were collected using a structured self-administered questionnaire which was adapted from a previous study and in-depth literature review. ${ }^{13,16}$ The questionnaire was prepared in English and deployed for the respondents. The questionnaire was checked thoroughly for objectivity and variable assessment before it was distributed to the data collectors. Half-day training was given to the data collectors and the supervisors on the study protocol, including the study objectives, the relevance of the study and confidentiality of information, respondent's rights, and informed consent. One supervisor was a nurse holding a bachelor science degree and two data collectors were nurses holding a diploma. This study was conducted in accordance with the Declaration of Helsinki: each study participant was well informed about the aim of the study, benefits, and risks; informed written consent was secured from study participants; study participants' confidentiality was maintained; no personal identifiers were used in the data collection questionnaire, and codes were used in place of them; the recorded data were not accessed by a third person, except the researcher; and data sharing will be enacted based on the consent and permission of research participants. The scoring method was adopted from a previous study; ${ }^{17,18}$ good knowledge and good practice was recoreded for nurses who scored above the mean result for the knowledge and practice questions. Poor knowledge and poor practice scores were given to nurses who scored below the mean result for the knowledge and practice questions .

\section{Data Processing and Analysis}

Data were entered into the computer using Epi Data version 3.1 and transported to Statistical Package for Social Sciences (SPSS) version 22.0 for analysis. Descriptive and inferential statistics were analyzed and presented. Initially, bivariate logistic regression was carried out to see the association of each independent variable with the outcome variable. Thereafter, to see the relationship of knowledge, practice, and socio-demographic and other variables, multivariable logistic regression was used. Variables with a $P$-value $\leq 0.2$ in the bivariate logistic regression were used in the multiple logistic regression analysis. $P$-value $\leq 0.05$ and $95 \%$ confidence level were considered as statistically significant.

\section{Result}

\section{Sociodemographic Characteristics of Nurses}

A total 105 nurses participated in the study, with a response rate of $100 \%$. Among the study participants, 
Table I Sociodemographic Characteristics of Nurses Working in Debre Tabor General Hospital, Ethiopia, 2019

\begin{tabular}{|l|l|l|l|}
\hline Variable & Category & Frequency & Percent \\
\hline Sex & Male & 43 & 40.6 \\
& Female & 62 & 59.4 \\
\hline Age & $20-30$ years & 61 & 58.1 \\
& $30-40$ years & 34 & 32.4 \\
& $>40$ years & 10 & 9.5 \\
\hline Religion & Orthodox & 95 & 90.5 \\
& Muslim & 8 & 7.6 \\
& Protestant & 2 & 1.9 \\
\hline Educational & Diploma Nurse & 37 & 35.2 \\
background & Degree (BSC & 68 & 64.8 \\
& Nurse) & & \\
\hline Marital Status & Single & 34 & 32.2 \\
& Married & 61 & 58.1 \\
& Divorced & 7 & 6.7 \\
& Widowed & 3 & 3.0 \\
\hline Work experiences & 55 years & 41 & 39.0 \\
& 5-10 years & 39 & 37.1 \\
& $\geq 30$ years & 25 & 23.8 \\
\hline
\end{tabular}

$59.4 \%$ were females. The median age was in the age category ranging from $25-30$ years (Table 1).

\section{Knowledge of Nurses About Oxygen Therapy}

The mean knowledge score of the participants was 4.95 \pm 2.45 . Only $63(60 \%)$ were aware that SOT should be administered to treat and prevent hypoxia, while 27 $(25.7 \%)$ nurses were aware that SOT is contraindicated for untreated pneumothorax. Regarding normal oxygen saturation, $54(51.4 \%)$ of them answered correctly. Almost half of the respondents $(55,52.2 \%)$ were aware that a non-rebreathing oxygen face mask with a reservoir bag is used to deliver a higher oxygen concentration than nasal prong. In this study, about $52 \%$ of the nurses had good knowledge whereas $48 \%$ of nurses had poor knowledge of oxygen therapy (Table 2).

\section{Practice of Nurses on Oxygen Administration}

Observational practice cheek lists were used to assess nurse's practice on supplemental oxygen administration. The mean practice score was $2.37 \pm 1.76$. Based on the observed practice of supplemental oxygen
Table 2 Nurses Knowledge on Supplemental Oxygen Therapy at Debre Tabor General Hospital, Ethiopia, 2019

\begin{tabular}{|c|c|c|c|}
\hline Variable & Category & Frequency & Percent \\
\hline $\begin{array}{l}\text { Supplemental Oxygen } \\
\text { therapy is used to prevent } \\
\text { and treat hypoxia }\end{array}$ & $\begin{array}{l}\text { Aware } \\
\text { Not aware }\end{array}$ & $\begin{array}{l}63 \\
54\end{array}$ & $\begin{array}{l}60.0 \\
51.4\end{array}$ \\
\hline $\begin{array}{l}\text { The normal oxygen } \\
\text { saturation for adult is } \\
95-100 \%\end{array}$ & $\begin{array}{l}\text { Aware } \\
\text { Not aware }\end{array}$ & $\begin{array}{l}42 \\
51\end{array}$ & $\begin{array}{l}40.0 \\
48.6\end{array}$ \\
\hline $\begin{array}{l}\text { Supplemental oxygen therapy } \\
\text { is indicated during surgery }\end{array}$ & $\begin{array}{l}\text { Aware } \\
\text { Not aware }\end{array}$ & $\begin{array}{l}64 \\
41\end{array}$ & $\begin{array}{l}61.0 \\
39.0\end{array}$ \\
\hline $\begin{array}{l}\text { Supplemental oxygen therapy } \\
\text { is indicated during shock }\end{array}$ & $\begin{array}{l}\text { Aware } \\
\text { Not aware }\end{array}$ & $\begin{array}{l}56 \\
49\end{array}$ & $\begin{array}{l}53.3 \\
46.7\end{array}$ \\
\hline $\begin{array}{l}\text { Pulse oximetry monitoring } \\
\text { is affected by nails varnish/ } \\
\text { paint, hypothermia, and or } \\
\text { patient position }\end{array}$ & $\begin{array}{l}\text { Aware } \\
\text { Not aware }\end{array}$ & $\begin{array}{l}18 \\
39\end{array}$ & $\begin{array}{l}17.2 \\
37.1\end{array}$ \\
\hline $\begin{array}{l}\text { Humidifier reduces the risk } \\
\text { of dry oxygen and its side- } \\
\text { effects }\end{array}$ & $\begin{array}{l}\text { Aware } \\
\text { Not aware }\end{array}$ & $\begin{array}{l}33 \\
17\end{array}$ & $\begin{array}{l}31.4 \\
16.2\end{array}$ \\
\hline $\begin{array}{l}\text { Non-rebreathing oxygen } \\
\text { face mask with a reservoir } \\
\text { bag is used to deliver higher } \\
\text { oxygen concentration than } \\
\text { a nasal prong }\end{array}$ & $\begin{array}{l}\text { Aware } \\
\text { Not aware }\end{array}$ & $\begin{array}{l}88 \\
72\end{array}$ & $\begin{array}{l}83.8 \\
68.6\end{array}$ \\
\hline $\begin{array}{l}\text { During oxygen therapy, } \\
\text { apply water based gauze if } \\
\text { lips or nose become dry }\end{array}$ & $\begin{array}{l}\text { Aware } \\
\text { Not aware }\end{array}$ & $\begin{array}{l}60 \\
45\end{array}$ & $\begin{array}{l}57.1 \\
42.9\end{array}$ \\
\hline $\begin{array}{l}\text { Supplemental oxygen is } \\
\text { contraindicated for } \\
\text { untreated pneumothorax }\end{array}$ & $\begin{array}{l}\text { Aware } \\
\text { Not aware }\end{array}$ & $\begin{array}{l}27 \\
73\end{array}$ & $\begin{array}{l}25.7 \\
74.3\end{array}$ \\
\hline
\end{tabular}

administration, only $33 \%$ of the nurses had good practice and the majority $(67 \%)$ of nurses had poor practice of supplemental oxygen administration. Only $21.9 \%$ and $27.9 \%$ of the nurses assessed oxygen saturation and vital signs during supplemental oxygen administration, respectively (Table 3 ).

\section{Factors Affecting Oxygen Therapy}

About two-thirds of nurses who had SOT training had good practice on supplemental oxygen administration. In this study, nurses who had a BSc degree were 10-times (adjusted odds ratio $[\mathrm{AOR}]=10.87,95 \% \mathrm{CI}=3.25-30.51$ ) more likely to have good practice of supplemental oxygen administration compared to those who had 
Table 3 Nurses Practice on Oxygen Administration in Debre Tabor General Hospital, Ethiopia, 2019

\begin{tabular}{|l|l|l|l|}
\hline Variable & Category & Frequency & Percent \\
\hline $\begin{array}{l}\text { Assess oxygen saturation } \\
\text { before administration }\end{array}$ & Yes & 40 & 38.1 \\
\hline No & 65 & 61.9 \\
\hline $\begin{array}{l}\text { Assess oxygen saturation } \\
\text { during administration }\end{array}$ & Yes & 29 & 27.6 \\
\hline No & 76 & 72.4 \\
\hline $\begin{array}{l}\text { administration } \\
\text { Collect all necessary }\end{array}$ & Yes & 32 & 30.5 \\
equipment before & No & 33 & 69.5 \\
administration & 72 & 31.4 \\
\hline Adjust the flow rate & Yes & 39 & 68.6 \\
appropriately during & No & 66 & 37.1 \\
administration & & 62.9 \\
\hline $\begin{array}{l}\text { Use appropriate device size } \\
\text { and way }\end{array}$ & Yes & 67 & 63.8 \\
\hline $\begin{array}{l}\text { Follow patients vital } \\
\text { signs during administration }\end{array}$ & $\begin{array}{l}\text { Yes } \\
\text { No }\end{array}$ & 23 & 36.2 \\
\hline
\end{tabular}

a diploma. Nurses who had good knowledge of SOT were 12-times $(\mathrm{AOR}=12.25,95 \% \mathrm{CI}=6.48-32.93)$ more likely to have good practice of supplemental oxygen administration than those who had poor knowledge of SOT (Table 4).

\section{Discussion}

Oxygen therapy is the administration of oxygen as a medical intervention, which can be for a variety of medical and surgical conditions. Patients can be affected by getting no oxygen or too little or too much oxygen. It is appropriate to provide the optimal concentration of supplemental oxygen to the acutely ill hypoxemic patient; inadequate oxygen administration may result in cardiac arrhythmias, tissue injury, renal injury, and ultimately cerebral damage. ${ }^{13}$

In this study, $48 \%$ of nurses had poor knowledge of oxygen therapy. This finding is comparable with research done in Beirut hospitals (55.1\%) and Eritrean hospitals (56.7\%), of nurses had a low level of knowledge regarding oxygen therapy, ${ }^{17,18}$ but lower than in Addis Ababa, Ethiopia, which shows that $63.8 \%$ of nurses had poor knowledge regarding oxygen therapy. ${ }^{14,15}$ This discrepancy might be due to the sample size, study setting, and study period difference. Research in Nottingham University Hospitals ${ }^{8}$ stated that nurses should know oxygen therapy indications, normal oxygen saturation at different ages, including normal respiration rates. This study approved that nurses who were working in the hospital during the study period and in the study areas have a knowledge gap on oxygen therapy. In our study the practice of nurses on oxygen therapy had a strong relation with nurses' knowledge, education level, availability of OT guidelines, and oxygen therapy training. This is in line with research done at Addis Ababa, Ethiopia, ${ }^{19}$ Turkey, ${ }^{20}$ and Nepal. ${ }^{21}$ The major challenges of oxygen administration in the hospital identified by the nurses were: inadequate knowledge of healthcare professionals regarding oxygen therapy, lack of training of nurses related to oxygen therapy, inadequate supply of equipment and oxygen, and unavailability of a standardized protocol for oxygen therapy. In this study, nurses do not have adequate knowledge about oxygen therapy. This finding is in line with research done in Addis Ababa, Ethiopia, ${ }^{14}$ Nepal, ${ }^{21}$ and Riyadh. ${ }^{13}$

The practice level of nurses on oxygen administration in this research showed that only $33 \%$ of the nurses had good practice. This finding is lower than studies conducted in Addis Ababa hospitals (43.4\%), ${ }^{19}$ Eritrean hospitals $(45 \%),{ }^{18}$ and Egypt hospital $(74.5 \%)^{16}$. This might be due to the lack of nurses training regarding OT, unavailability of oxygen administration guidelines, and increased workload of nurses (because nurses' activities are more than their job description). Based on this study barrier, the factors which could affect the good practice of oxygen administration, are the unavailability of a standardized protocol about oxygen therapy, lack of training about OT, and an inadequate supply of $\mathrm{O}_{2}$ and delivery system. This finding is supported by research conducted in Egypt, ${ }^{16}$ Addis Ababa, Ethiopia, ${ }^{19}$ and Eritrea. ${ }^{18}$

\section{Conclusions and Recommendations}

In conclusion, this study demonstrates that there is a clear gap of knowledge and practice among nurses related to SOT use. The possible reason for this gap includes a shortage of training on SOT, unavailability of national as well as hospital SOT guidelines and excessive nurse workload. Education programs on the occupational use of SOT through in-service training and workshops are important to raise the awareness and practice of nurses about SOT. Hospital nurses also need to be made aware and skillful regarding the updated guidelines for SOT. The unavailability of well- 
Table 4 Logistic Regression Analysis for Practice of Nurses on Oxygen Therapy in Debre Tabor General Hospital, Ethiopia, 2019

\begin{tabular}{|c|c|c|c|c|}
\hline \multirow[t]{2}{*}{ Variable } & \multicolumn{2}{|c|}{ Practice Level } & \multirow[t]{2}{*}{ COR $(95 \% \mathrm{Cl})$} & \multirow[t]{2}{*}{ AOR $(95 \% \mathrm{CI})$} \\
\hline & Good, n (\%) & Poor, n (\%) & & \\
\hline \multicolumn{5}{|l|}{ Sex } \\
\hline Male & $17(39.5)$ & $26(60.5)$ & I & I \\
\hline Female & $18(29.0)$ & $44(7 \mid .0)$ & $0.626(0.275-1.422)$ & $1.57(0.306-8.06)$ \\
\hline \multicolumn{5}{|l|}{ Educational Status } \\
\hline Diploma Nurse & $25(67.6)$ & $12(32.4)$ & 1 & I \\
\hline Degree (BSC Nurse) & $10(14.7)$ & $58(85.3)$ & $12.08(4.62-31.60)^{*}$ & $10.87(3.25-30.5 \mathrm{I})^{*}$ \\
\hline \multicolumn{5}{|l|}{ Age of respondents } \\
\hline 20-30 years & $13(36.1)$ & $23(63.9)$ & I & 1 \\
\hline $30-40$ years & $17(34.7)$ & $32(65.3)$ & $0.94(0.38-2.31)$ & $1.04(0.26,-.12)$ \\
\hline$\geq 40$ years & $5(25.0)$ & $15(75.0)$ & $0.59(0.17-1.99)$ & $0.63(0.11-3.59)$ \\
\hline \multicolumn{5}{|l|}{ Supplemental Oxygen therapy training } \\
\hline Yes & $25(67.6)$ & $12(32.4)$ & II.08 (4.62-31.60)* & $9.71(3.94-27.48)^{*}$ \\
\hline No & $10(14.7)$ & $58(85.3)$ & I & I \\
\hline \multicolumn{5}{|l|}{ Availability of SOT guideline } \\
\hline Yes & $25(65.8)$ & $13(34.2)$ & $10.96(4.24-28.32)^{*}$ & $8.2 \mathrm{I}(4.0 \mathrm{I}-24.78)^{*}$ \\
\hline No & $10(14.9)$ & $57(85.1)$ & I & I \\
\hline \multicolumn{5}{|l|}{ Adequate supply of $\mathrm{O}_{2}$ and delivery system } \\
\hline Yes & $24(63.2)$ & $14(36.8)$ & $8.72(3.47-21.96)$ & $6.21(3.56-20.23)^{*}$ \\
\hline No & II (I6.4) & $56(83.6)$ & I & I \\
\hline \multicolumn{5}{|l|}{ Workload affects SOT } \\
\hline Yes & $23(65.7)$ & $12(34.3)$ & $9.26(3.64-23.58)^{*}$ & $0.452(0.01-25.43)$ \\
\hline No & $12(17.1)$ & $58(82.9)$ & I & 1 \\
\hline \multicolumn{5}{|l|}{ Knowledge about SOT } \\
\hline Good knowledge & $33(60.0)$ & $22(40.0)$ & I5.24 (7.92-38.5I)* & $12.25(6.48-32.93)^{*}$ \\
\hline Poor knowledge & $2(4.0)$ & $48(96.0)$ & I & I \\
\hline
\end{tabular}

Note: $* P \leq 0.05$.

Abbreviations: $\mathrm{N}$, number; \%, percent; COR, crude odds ratio; $\mathrm{AOR}$, adjusted odds ratio; $\mathrm{Cl}$, confidence interval.

functioning equipment and poor maintenance of nonfunctional oxygen machines are the most serious and additional burdens of nurses to SOT. Therefore, the hospital should have well-trained and always stand by the biomedical technologists to solve such problems.

\section{Abbreviations}

SOT, supplemental oxygen therapy; WHO, World Health Organization; BSc, Bachelor of Sciences; $\mathrm{O}_{2}$, oxygen; SPSS, Statistical Package for Social Sciences.

\section{Data Sharing Statement}

The datasets used in this study are available from the corresponding author and can be accessible through reasonable request.

\section{Ethics Approval and Consent to Participate}

The research proposal was approved by Debre Tabor University research ethical committee. This study was conducted in accordance with the Declaration of Helsinki: each study participant was well informed about the aim of the study, benefits, and risks; informed written consent was secured from study participants; study participants' confidentiality was maintained; no personal identifiers were used in the data collection questionnaire, and codes were used in place of them.

\section{Acknowledgments}

The authors are grateful to the data collectors and study participants. 


\section{Author Contributions}

All authors made substantial contributions to the conception and design, acquisition of data, or analysis and interpretation of data; took part in drafting the article and revising it and agreed to submit to the current journal; gave final approval of the version to be published; and agree to be accountable for all aspects of the work.

\section{Funding}

There is no funding to report.

\section{Disclosure}

The authors declare that they have no conflicts of interest for this work.

\section{References}

1. Guidelines for acute oxygen therapy for western Australian hospitals. 2011.

2. World Health Organization. Essential Medicines and Health Products: WHO MODEL Lists of Essential Medicines. Geneva: WHO; 2016:33-47.

3. McMullan J, Rodriquez D, Hart KW, et al. Prevalence of prehospital hypoxemia and oxygen use in trauma patients. Mil Med. 2013;178 (10):1121-1125. doi:10.7205/MILMED-D-13-00126

4. Adib-Hajbaghery M, Maghaminejad F, Paravar M. The quality of pre-hospital oxygen therapy in patients with multiple trauma: a cross-sectional study. Iran Red Crescent Med J. 2014;16(3). doi:10. 5812/ircmj. 14274

5. Hardinge M, Annandale J, Bourne S, et al. British thoracic society home oxygen guideline development group; British Thoracic Society standards of care committee. British Thoracic Society guidelines for home oxygen use in adults. Thorax. 2015;70(Suppl 1):i1-i43. doi:10.1136/thoraxjnl-2015-206865

6. Beasley R, Chien J, Douglas J, et al. Thoracic Society of Australia and New Zealand oxygen guidelines for acute oxygen use in adults:'swimming between the flags'. Respirology. 2015;20(8):1182-1191. doi:10. 1111/resp. 12620

7. Newnam KM. Oxygen saturation limits and evidence supporting the targets. Adv Neonatal Care. 2014;14(6):403-409. doi:10.1097/ANC. 0000000000000150
8. Kane B, Decalmer S, O'Driscoll BR. Emergency oxygen therapy: from guideline to implementation. Breathe. 2013;9(4):246-253. doi:10.1183/20734735.025212

9. Budinger GRS, Mutlu GM. Balancing the risks and benefits of oxygen therapy in critically III adults. Chest. 2013;143(4):1151-1162. doi:10.1378/chest.12-1215

10. McGloin S. Administration of oxygen therapy. Nurs Stand. 2008;22 (21):46-48. doi:10.7748/ns2008.01.22.21.46.c6416

11. O'Driscoll BR, Howard LS, Earis J, et al. British thoracic society guideline for oxygen use in adults in healthcare and emergency settings. BMJ Open Respir Res. 2017;4(1):e000170-e000170. doi:10. 1136/bmjresp-2016-000170

12. Nippers I, Sutton A. Oxygen therapy: professional compliance with national guidelines. Br J Nurs. 2014;23(7):382-386. doi:10.12968/ bjon.2014.23.7.382

13. Aloushan AF, Almoaiqel FA, Alghamdi RN, et al. Assessment of knowledge, attitude and practice regarding oxygen therapy at emergency departments in Riyadh in 2017: a cross-sectional study. World J Emerg Med. 2019;10(2):88. doi:10.5847/wjem.j.1920-8642.2019. 02.004

14. Weldetsadik AS. Assessment of nurse's knowledge, attitude and practice about oxygen therapy at emergency departments of one federal and three regional hospitals in Addis Ababa, Ethiopia. 2015.

15. WHO. Human Papillomavirus and Related Cancers in Ethiopia: Summary Report 2010. CFTOKEN. 2010.

16. Mayhob M. Nurses' knowledge, practices and barriers affecting a safe administration of oxygen therapy. J Nurs Health Sci. 2017;7 (3):42-51.

17. Daou BEL, Hussein K. Assessment of nurses' knowledge and interventions regarding oxygen therapy and related complications in Beirut hospitals. Health Care Curr Rev. 2018;6.

18. Ghebremichael FG, Thomas LM, Yohannes A, et al. Assessment of nurses' knowledge, attitude and practice about oxygen therapy in emergency and ICU departments of Orotta National Referral Hospital. Int J Med Health Prof Res. 2019;6(1):102-111.

19. Lemma G. Assessment of nurses knowledge, attitude and practice about oxygen therapy at emergency departments of one federal and three regional hospitals in addis ababa, Ethiopia. 2015.

20. Demirel H, Erek Kazan E. Knowledge levels of nurses about oxygen therapy in Turkey. Int J Health Serv Res Policy. 2020;5(1):1-14. doi:10.33457/ijhsrp.700150

21. Piryani RM, Ma PR, Suneel P, Shama P, Jasmine G, Pooja S. Knowledge of Staff Nurses about Oxygen Therapy Working in Intensive Care Areas of Universal College of Medical Sciences Teaching Hospital Bhairahawa, Nepal. EC Emergency Medicine and Critical Care. 2020:1-10.

\section{Publish your work in this journal}

The Open Access Emergency Medicine is an international, peerreviewed, open access journal publishing original research, reports, editorials, reviews and commentaries on all aspects of emergency medicine. The manuscript management system is completely online and includes a very quick and fair peer-review system, which is all easy to use. Visit http://www.dovepress.com/testimonials.php to read real quotes from published authors. 